\title{
Amine-Directed Alkyl-Alkyl Suzuki Reactions
}

Key words

nickel

Suzuki coupling

alkyl-alkyl coupling<smiles>CCCC(C)CN(C)c1ccc(OC)cc1</smiles>

$78 \%$ yield (84\% ee)
$+\quad(9-\mathrm{BBN}) n-\mathrm{Hex}$

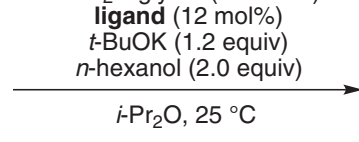

ligand:

$\mathrm{Ar}$

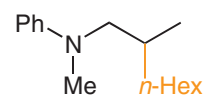

$84 \%$ yield ( $88 \%$ ee)

$$
\mathrm{Ar}=1-\mathrm{Naph}
$$<smiles>Cc1cccc(N(CC(C)CCC[SeH])C(C)([O-])O[Na])c1</smiles>

\section{$63 \%$ yield} ( $91 \%$ ee)<smiles>CCC(C)CN(C)c1cccc(F)c1</smiles>

$70 \%$ yield (92\% ee)
Significance: This work reports the development of a stereoconvergent aryl amine directed alkylalkyl Suzuki coupling. In this protocol, unactivated secondary alkyl chlorides serve as substrates and the desired products are generally obtained with good enantioselectivity using a $C_{2}$-symmetric 1,2-diamine ligand.
Comment: Structure-enantioselectivity studies indicated that the aryl amine is the primary coordination site to the catalyst. Consistently, the introduction of an additional methylene unit between the aryl amine moiety and the chloride leads to a product with essentially no enantiomeric excess. 